\title{
Effectiveness of Cognitive Conflict Strategy in Improving Academic Achievement and Modifying Sex Education Misconceptions in Science Course among Intermediate Second-Grade Students
}

\author{
Nisreen H. Subahi ${ }^{1, *}$ \\ ${ }^{1}$ Faculty of Education, University of Jeddah, Saudi Arabia \\ *Correspondence: Faculty of Education, University of Jeddah, Saudi Arabia. E-mail: d.alsubahi@hotmail.com
}

Received: February 11, 2019 Accepted: March 20, $2019 \quad$ Online Published: April 12, 2019

doi:10.5430/wje.v9n2p90 URL: https://doi.org/10.5430/wje.v9n2p90

\begin{abstract}
The current study aimed at identifying the effectiveness of cognitive conflict strategy in improving academic achievement and modifying sex education misconceptions in the Science course among intermediate second-grade students in Jeddah. Based on the cognitive conflict strategy, a teacher guide was prepared for teaching Family Planning and Reproduction Chapter. In addition, an achievement test and a misconception scale of sex education are prepared. The sample consisted of 56 students equally distributed to an experimental group taught using the cognitive conflict strategy and a control one taught using the traditional method. Results revealed that there were statistically significant differences between the average scores of the experimental and the control groups in the achievement test and the misconception scale of sex education, favoring the experimental group. The study recommended holding training courses, workshops, conferences and synopses for Science teachers and supervisors on the use of cognitive conflict strategy.
\end{abstract}

Keywords: cognitive conflict strategy; achievement; misconceptions; sex education

\section{Introduction}

In the third millennium, man faces rapidly changing moral and educational values. Hence, incorporating sex education in our lives and schools has become more urgent than ever. The radical changes in values and morals necessitate supporting the acquisition of sex knowledge and the identification of its scientific aspects and importance to human experience as a whole. Alaamarin (2011) and Jumah (2008) agree that attention should be paid to sex education as one of the most important educational and social issues. Affording sex education based on proper scientific and teaching methods helps the family raise up their children and guide their conduct. It also helps the student behave well, be able to adapt, understand human sexuality, and acquire sound and accurate scientific information. According to Mosher (2005) and Al-Kashah (2004), sex education contributes to achieving social integration and reducing abnormal behavior. However, curriculum developers should select the appropriate vocabularies and subjects for different educational stages. According to Becy's report about a seminar on sex education (2010), teaching sex education is necessary for different educational stages, taking into consideration selecting the suitable concepts and subjects for learners, which should be included in various curricula.

In the Arab countries, attention to sex education has been paid in the framework of population education projects in public schools. Accordingly, subjects were relevant to health and population, the human reproduction system anatomy, reproduction physiology, family planning, and sexual diseases transition. These countries include Morocco, Tunisia, Egypt, Yemen, Syria, Jordan and Palestine (Al-Jokhdar, 2000). On March $2^{\text {nd }}, 2017$, Tlemcen University-Algeria sponsored the National Forum of Sexual Education and Health: Reality, Vision, and Challenges. The forum recommended the significance of building community culture dealing with the best ways and approaches to face challenges related to sexual education and health. In The National Symposium of Comprehensive Sexual Education (2017), several experts and specialists called for the importance of including sexual education in the educational programs (Arab Office of Education in Gulf States, 2017).

Given the importance of sex education, many studies have dealt with it. Orji \& Esimani (2003) measured parents', teachers' and students' knowledge of sex education and their level of acceptance of its introduction into the school 
curriculum in Nigeria. Results concluded that the majority of parents, teachers and students supported the introduction of sex education into the school curriculum and believed that it would enhance healthy relationships between opposite sex, prevent transmission of venereal infections, provide the knowledge of sexual interactions and educate students about the basic processes of human reproduction.

Fanlder et al. (2004) assessed medical students' theoretical confidence in dealing with sexual health consultations. Results revealed that students who had participated in delivering peer-led sex education felt significantly more confident in discussing sexual health issues than students who had not participated in the project.

Ogunjimi (2006) investigated the disposition of students and parents towards the inclusion of sex education in the school curriculum in Cross River State. Results concluded that the majority of the students and parents were in support of the inclusion of sex education in the school curriculum. Healthy Youth Alliance commissioned a research project to learn about the sexuality education and prevention programs and topics related to sexual health and family life taught in Washington's public schools. The project results showed that all American schools curricula include sex education for all educational stages and sex education teachers are required to have a previous preparation or training on sex education (Alison, 2007).

Ramiro (2008) assessed perceptions and attitudes regarding sex education among middle and high school teachers in Portugal. Teachers showed a straightforward attitude towards sex education and assessed it as moderately/highly important. Berger et al. (2007) analyzed teachers' conceptions of the topic of sex education. It concluded that the factors that correlate most closely with the teachers' conceptions are religion, the level of teaching (educational stage), knowledge related to sex education, teachers' teaching skills and class teaching practices.

Reis et al. (2006) analyzed the significance of sex education in schools and its effects on promoting healthy sexual behavior among university students. Results showed that students who had sex education at school mentioned having had fewer sexual risk behaviors.

Sex education is a process conducted by a teacher in the school or a parent at home aimed at providing children and teenagers with scientific information and sound attitude towards sexual matters in accordance with their mental and physical development. ALFord (2008) believed that effective sex education should aimed at achieving significant behavior changes, showing respect to social values, considering the needs of the community and adopting participatory approach between the school and the family. The subjects of sex education should be suitable to students' age and should be taught by using the proper teaching strategy.

Abdel Alazeem (2008), Alqadi (2006) and Shulman (2001) agreed that sex education objectives include minimizing wrong sex information and ideas, modifying distorted attitudes toward sexual behavior patterns, protecting students from irresponsible sexual experiences, constructing positive attitudes toward sexuality and building a healthy social structure. It also aimed at educating young people about the correct conduct of sexual relations to protect them from the transmission of venereal diseases resulting from unhealthy sexual relations.

Alaabidly (2001) reported that reluctance to face sex education challenges means to deliberately insist on concealing one of the most important features of student's physical and psychological development. It suggests that neglecting sex education by the concerned people (parents, teachers, specialists, and scholars of religion) urge adolescents to follow unauthentic media, including sex magazines, porn TV channels, porn websites, as well as peers who play the role of educators in teaching and presenting sex issues, which contradict Islamic teachings and values of the Arab society. This, in turn, has resulted in serious behaviors among adolescents and steadily increasing transmission of venereal diseases.

During childhood and adolescence stages, misconceptions of sex education are easily cultivated and rooted in children and adolescents' minds for a long time and affect their future behavior. Hence, educators should pay attention to sex education in order to help the adolescent understand his/her sexual compatibility. It is dangerous to allow young people get sex information from unsafe sources, as many parents and educators neglect sex education and have no information or correct answers to their children's questions. Accordingly, both the family and the school need to have a planned sex education based on scientific studies and research conducted by psychologists, sociologists, doctors and educators (Zahran, 2005).

In relation to sex education, curricula play an important role in providing students with guidance, the right knowledge, practices and correct behaviors in order to keep students safe and to nurture a conscious intellectual generation (Al-Zind \& Obaidat, 2010). It can be concluded that sex education should seek to achieve goals commensurate with the community and its issues. It is a mean and not an end, as its goals varies according to society, customs and traditions.

Science course is one of the most relevant subjects to the student's life. It plays a significant role in providing students 
with the concepts, skills and attitudes that help them successfully address various problems. In this regard, Najdi et al. (2003) indicated that science curricula are essential for teaching students how to deal with sexual issues and developing their scientific knowledge, skills, thinking methods, and tendencies for enhancing the concept of protection and prevention among students.

An interview is conducted to investigate the viewpoints of some Science supervisors and teachers of the intermediate stage about the status of sex education among students. They confirmed that there are many misconceptions about sex education topics and stressed the need to use modern teaching methods to motivate student to correct and develop their concepts. Moreover, a misconception test was conducted on a pilot sample consisted of 56 intermediate second-grade students. 46 students, i.e. $14.82 \%$, had misconceptions about the scientific content of the sex education curricula.

The credible and appropriate teaching methods and strategies used to introduce sex information are the most important anchor of sex education. They help provide the students with clear and honest answers to their inquiries, in a manner suitable for their level of mentality, maturity and development (Farton, 2004) (Salah, 2000).

Recently, modern teaching strategies have aimed to correct and modify misconceptions among learners through applying the principles of the constructivism theory (Mady, 2011). Based on Piaget's theory of cognitive development, cognitive conflict strategy means that conflict in learner's mind can lead to learning. In the learner's cognition, the meaning is self-constructed through a mental effort and resistance to conceptual change (Mady, 2011).

Cognitive conflict is defined as a conceptual scheme belongs to constructivism philosophy and it is based on the learner's positivity. It is used by the teacher as an educational tool in the educational environment for replacing misconceptions with alternative correct conceptions (Mady, 2011).

According to González - Espada, Birriel, and Birriel (2010) and Abdul Wareth \& Said (2012), teaching by cognitive conflict strategy passes through the following stages:

1. Creating conflict: students' attention is attracted through demonstrating an unexpected event. They are motivated to ask the teacher about these discrepant demonstrations.

2. Searching for solution: students become eager to find a solution to these discrepant demonstrations. Activities necessary for solving this conflict are prepared and students become active in observation, data registration, classification, prediction, and experimentation. They also learn a large part of the correct content of lessons.

3. Solving the conflict: practicing activities that help the students solve the conflict themselves and they come up with answers to several questions, instead of listening to some theoretical explanations. They acquire several skills such as data collection, observation, cooperation, and asking questions. As a result, students achieve cognitive balance by offering a solution to cognitive conflict; a misconception is replaced by a sound scientific one.

Pyram (2002), Tsai (2003), Albeleesi (2006), Baz \& Bwanah (2008) and Agha \& Lulu (2009) agreed to the effectiveness of cognitive conflict strategy in teaching science. It helps modify students' misconception about natural phenomena, correct their attitude towards Science, and motivate them to search for explanations for the discrepant events. In addition, adopting cognitive conflict as teaching strategy creates an interesting and exciting classroom environment, since students make and test hypotheses to correct their misconceptions. It improves scientific thinking skills, critical thinking and creativity among learners. They are able to correctly link between scientific concepts and reach logical sequences of the scientific conceptions. Discussions of cognitive conflict maps enhance peers participation and the learners' positive, active and effective role in the educational process. Through active participation, the teacher can consider individual differences and develop attitudes towards studying Science among students.

Many studies have proved the effectiveness of applying cognitive conflict strategy in modifying Science misconceptions among students (Al-Mahdi, 2017) (Al-Rubaiyi et al., 2015) (Jawad, 2015) (Al-Otaibi, 2015) (Alabous \& Alani, 2013) (Almamouri, 2011) (Albayati \& Mehdi, 2009) (Alhalafawi, 2009) (Abu Halima, 2008) (Baz \& Bwanah, 2008) (Ahmad, 2008) (Tolba, 2006) (Albeleesi, 2006) (Salem, 2006) (Demirciog et al., 2005) (Zohar \& Kravetsky, 2003) and (Tsai, 2003).

The current study aimed to identify the effectiveness of applying cognitive conflict strategy in modifying sex education misconceptions among intermediate second-grade students in Jeddah. 


\section{Statement of the Problem}

Due to the prevalence of sex education misconceptions, intermediate second-grade students show a low achievement level in Science. They memorize definitions and scientific concepts without actually understanding their meaning. This requires looking for teaching strategies that contribute to modifying their misconceptions and improving their academic achievement. To address this problem, the current study attempts to answer the following main question: What is the effectiveness of cognitive conflict strategy in improving Science achievement and modifying sex education misconceptions among intermediate second-grade students?

The main question is further subdivided into the following questions:

1. What is the effectiveness of applying cognitive conflict strategy in teaching sex education concepts in Science achievement among intermediate second-grade students?

2. What is the effectiveness of applying cognitive conflict strategy in modifying sex education misconceptions in Science curricula among intermediate second-grade students?

\subsection{Objectives}

The present study aims to identify:

1. The effectiveness of applying cognitive conflict strategy in teaching sex education concepts in Science achievement among intermediate second-grade students.

2. The effectiveness of applying cognitive conflict strategy in modifying sex misconceptions in Science curricula among intermediate second-grade students.

\subsection{Significance}

The current study is of significance as it represents an objective response to educators' call for paying attention to sex education, affording new teaching strategies suitable for its scientific content, and modifying sexual misconceptions among students. It also introduces a list of the most important sex education concepts necessary for intermediate stage students in Science curricula. It provides a teacher guide to teach sex education concepts to the intermediate second-grade students using the cognitive conflict strategy. It affords an achievement test to measure the achievement of the intermediate second-grade students in sex education concept in Science course. It provides a test to measure the prevalence of sexual misconceptions among intermediate second-grade students.

\subsection{Limitations}

Temporal limits: Family Planning and Reproduction Chapter taught to the intermediate second-grade students in second semester of the academic year 2017-2018.

Spatial and human limits: a group of the intermediate second-grade students in Jeddah.

Objective limits: Bloom's taxonomy (memorization, comprehension, application, and analysis).

\subsection{Hypotheses}

1. There is a statistically significant difference in the average scores of the experimental group students (taught by cognitive conflict strategy) and the control group (taught by the traditional method) in the post-test of academic achievement, favoring the experimental group.

2. There is a statistically significant difference in the average scores of the experimental group students (taught by cognitive conflict strategy) and the control group (taught by the traditional method) in the post-test of sex misconceptions, favoring the experimental group.

\section{Definition of Terms}

Effectiveness: It is procedurally defined as the effect that can be made by the application of cognitive conflict strategy as an independent variable on the dependent variable (achievement and misconceptions).

Cognitive conflict strategy: It is procedurally defined as a set of educational actions and situations designed by Science teacher to put the intermediate second-grade students in a state of cognitive uncertainty concerning their sex education concepts of (family planning and reproduction chapter). Then these misconceptions are to be modified by following several steps: identifying students' misconceptions, constructing conflict, students' search for a solution to this conflict, and providing a solution.

Traditional method: It is procedurally defined as a process in which the teacher presents the scientific concepts and 
processes and then explaining and discussing them with students without active participation or interaction.

Academic achievement: It is procedurally defined as the extent to which the intermediate second-grade students understand the information and knowledge they have gained about sex education concepts in the Science curriculum through the application of the cognitive conflict strategy. The level of student academic achievement is identified by the scores they obtain in the test prepared for this purpose.

Misconceptions: It is procedurally defined as wrong sexual ideas prevalent among intermediate second-grade students concerning the chapter of "Family Planning and Reproduction".

Modifying misconceptions: It is the process of replacing sexual misconceptions with correct sexual concepts among intermediate second-grade students by merging, replacing or adding through students' correct answers to the questions of sexual misconception test prepared for this purpose .

Sex education: It is procedurally defined as an educational process that involves providing intermediate second-grade students with knowledge extracted from facts, concepts, principles and generalizations related to family learning and reproduction. It aimed at providing them with skills, attitudes, values and habits required for organizing their sexual lives and ensuring their psychological and physical health.

\section{Conceptual Framework \& Literature Review}

\subsection{Sex Education}

The teacher should adopt specifically scientific and proper teaching strategy to provide the student with clear and explicit information. Science is the most appropriate subject for introducing sexual information to students. The science teacher can instruct several topics, such as the anatomical and sexual differences between genders, adolescence challenges and physical changes, biological processes, reproduction, mating, coupling, pregnancy, embryo and birth. Sexual health is of great importance, including subjects of growth, functions of glands, secondary sexual functions of genital glands, reproductive anatomy and the rules of protecting the teenager general and sexual health (Abdullah \& Yawar, 2012).

Sex education is a very important pillar of sound education, as it aims at preparing a well-educated generation who is aware of the scientific and sexual facts. Various communities, in general, and the Arabic community, in particular, adopt a conservative and cautious attitude towards sex education and any discussion related to sex. Some people consider the inclusion of sex education in curricula is against the prevailing social customs and traditions. It should be noted that educational issues cannot be separated from social issues, as they represent together the way to reach a civilized society. Accordingly, while addressing the issues of sex education, the impact of social factors on constituting individuals attitude should be considered. In other words, sex cannot be instructed in a vacuum, but as an aspect of human life that contribute to and affect the comprehensive social structure.

\subsection{Cognitive Conflict Strategy and Misconceptions}

Misconceptions are one of the most prevalent challenges that face not only students, but teachers as well. It means that the learner has an unaccepted interpretation (not necessarily wrong) of a given concept resulted from a particular instruction activity (Zeitoun, 2002). Learners attend the class while they have a set of ideas and conceptions about their surrounding phenomena, which may sometimes contradict the scientifically correct perspective; such conceptions represent an obstacle to learners' acquisition of correct scientific conception (Alnashiry, 2008).

Accordingly, Science teacher has to help students modify the misconceptions rooted in their cognitive structure. The teacher can perform this task depending on several strategies, such as engaging students in an activity or solving a problem effectively and accepting all students' opinions even if they are incorrect and directing their ideas on the right track. Using students' conceptions and ideas in directing the lesson and giving opportunities to test their ideas even if they are wrong. Students should be given opportunities to search for knowledge and information. The teacher should consider students' previous conceptions and alternative concepts without challenging their misconceptions (Maximos, 2003).

While applying cognitive conflict strategy in teaching science, the teacher has to consider the best suitable method of presenting the discrepant events, the right time of examining the problem and determining its aspects, and reaching the unexpected event. Discussion of results in the context of theoretical learning enhances the detection of facts and concepts, which explain the unexpected event (Bahjat, 2001). Hence, the teacher plays a key and intrinsic role in the success of cognitive conflict instruction. Based on experience and professionalism, the teacher can successfully modify students' misconceptions through changing the class planning, focusing on the use of diverse activities that encourage 
student participation and cooperation and training them on problem solving. Besides, textbooks, videos, computer programs and external books can be effectively employed. Modern evaluation methods such as observation and reports can be employed to watch students' trends, attitudes and behavior, instead of criticism. A good teacher listens to students' views, tries to correct their answers, and encourages them to think and adopt new ideas (Alabous \& Alani, 2013).

It can be excluded that, before teaching a new subject, the students' previously rooted concepts, definitions and rules should be tested. The teacher should create the appropriate atmosphere of enthusiasm and thrill when presenting the discrepant events. Exciting cognitive conflict maps, student guidance, raising question and discussions and teamwork to resolve the contradiction enable the modification of the prevailing misconception.

According to (Mady, 2011) the student contributes to the successful application of the cognitive conflict strategy as he/ she plays an active role in the process of learning through participating in discussions, making hypotheses and constructing visions. Hence, the passive reception of information through listening and reading is replace by the active and collective acquisition of knowledge. The student also has to employ his creativity in discovering and rediscovering knowledge.

Cognitive conflict strategy achieves a balanced mental, social and psychological development among students, thus achieving the goals of education. It prepares students to adapt to their environment and society. They become able to pass paradoxical events through proper thinking and problem solving skills, as they ask questions, employ their abilities, and record data and observations to reach a scientific interpretation of any discrepant events.

Given the importance of cognitive conflict strategy among the students, several studies have been conducted and proved its effectiveness in modifying misconceptions. Al-Mahdi (2017) identified the effectiveness of discrepant events in modifying misconceptions and developing the problem solving skills in Chemistry among the tenth grade students in the schools of Tulkarem Education Directorate. It concluded the effectiveness of the strategy in modifying misconceptions.

Abdul Wareth \& Said (2012) proved the effectiveness of the cognitive conflict strategy in modifying misconceptions in Physics and developing critical thinking among first-grade secondary students.

Tolba (2006) aimed at identifying the effectiveness of using the cognitive conflict maps in correcting some alternative conceptions on the physical issues among the $1^{\text {st }}$ secondary grade students. Results showed the effectiveness of the strategy in correcting misconceptions among participants. Albeleesi (2006) examined the effect of using contradictions strategy on modifying some scientific misconceptions among tenth grade students. Results concluded the effectiveness of the strategy in correcting misconceptions among the experimental group students.

Tsai (2003) identified the implications of using cognitive conflict maps as an educational technique to change misconceptions among eighth grade students in electrical circuits and networks in Science. Results stressed the effectiveness of the strategy in modifying the sample misconceptions compared to the traditional method.

\section{Methodology and Procedures}

\subsection{Method}

The quasi-experimental approach was used to measure the effectiveness of cognitive conflict strategy in developing academic achievement and modifying some sex education misconceptions in the Science course among intermediate second-grade students. Two equal groups were selected: a control group that was taught by using the traditional method and an experimental group that was taught using the cognitive conflict strategy. Academic achievement test and misconceptions test were pre- and post- applied to participants.

\subsection{Sampling and Population}

The study population was represented by all the intermediate second-grade students in Jeddah. The sample was randomly selected and consisted of 56 intermediate second-grade students in Jeddah, equally distributed to two groups: an experimental group (28 students) and a control one (28 students).

\subsection{Tools}

1. List of sex education concepts

a) Selection of the scientific content

The chapter entitled (Family Planning and Reproduction) in Science course for intermediate second-grade students was selected as the field of the current research, as $85 \%$ of the subjects of the sample had misconceptions about the 
concepts relevant to the scientific content selected. This was reported in the pilot test made by the author in the second semester of the academic year 2017/2018. In addition, the chapter includes a large amount of new scientific information about sex education concepts, which help the learner understand the emergent physical changes during adolescence and facing real life situations.

b) Analysis of the scientific content according to sex education concepts

The topic contents were analyzed to specify the most important topics including sex education concepts by the use of unified ideas.

c) Validity

The analysis results were submitted to (5) reviewers specialized in Science curriculum and instruction and psychology to give their remarks on the validity of this analysis. In the light of their remarks and feedback, necessary modifications were made. Then, a final list of sex education concepts necessary for intermediate stage students was prepared.

d) Reliability

The author and a teacher analyzed the textbooks under investigation and the coefficient of analysis was estimated. Table 1 shows the high value of content reliability coefficient, as it scored (0.98).

Table 1. Results of the Content Analysis Reliability

\begin{tabular}{lccc}
\hline \multicolumn{1}{c}{ Analysis no. } & Topics & Agreed-on topics & Reliability coefficient \\
\hline First (the author) & 25 & 24 & 0.98 \\
Second (the teacher) & 24 & & \\
\hline
\end{tabular}

\section{Achievement test}

An achievement test is set for measuring the difference in the achievement level of the students in the chapter of (Family Planning and Reproduction) in science course. The target chapter's content topics were specified and given relative weight, as shown in table 2.

Table 2. Significance and Relative Weights of the Chapter's Content Topics

\begin{tabular}{|c|c|c|c|c|c|c|c|c|c|}
\hline No. & Topics & $\begin{array}{l}\text { No. } \\
\text { of } \\
\text { pages }\end{array}$ & $\%$ & $\begin{array}{l}\text { No. of } \\
\text { classes }\end{array}$ & $\%$ & $\begin{array}{l}\text { No. of } \\
\text { objectives }\end{array}$ & $\%$ & $\begin{array}{l}\text { relative } \\
\text { weight }\end{array}$ & Significance \\
\hline 1 & $\begin{array}{l}\text { Endocrine } \\
\text { gland System }\end{array}$ & 9 & 19.56 & 3 & 25 & 27 & 28.4 & 24.32 & 2 \\
\hline 2 & $\begin{array}{l}\text { Reproduction and } \\
\text { endocrine } \\
\text { gland system }\end{array}$ & 11 & 23.91 & 3 & 25 & 26 & 27.3 & 25.40 & 1 \\
\hline 3 & $\begin{array}{l}\text { Male and female } \\
\text { genital system }\end{array}$ & 11 & 23.91 & 2 & 16.7 & 18 & 18.9 & 19.84 & 3 \\
\hline \multirow{3}{*}{$\begin{array}{l}4 \\
5\end{array}$} & Phases of man's life & 8 & 17.39 & 2 & 16.7 & 13 & 13.7 & 15.93 & 4 \\
\hline & Menstruation and & & & & 16.7 & & & & \\
\hline & $\begin{array}{l}\text { hormone } \\
\text { development }\end{array}$ & 7 & 15.22 & 2 & & 11 & 11.6 & 14.51 & 5 \\
\hline Total & & 46 & 100 & 12 & 100 & 95 & 100 & 100 & \\
\hline
\end{tabular}

The behavioral objectives of the Chapter were set and Bloom's classification was adopted to assess students' achievement level. The unit objectives were confined to the first four levels (memorization, comprehension, application, and analysis). Thus, the relative weights of levels of objectives were given based on the analysis results, as shown in table 3. 
Table 3. Specifications of the Achievement Test

\begin{tabular}{|c|c|c|c|c|c|c|c|}
\hline \multirow{2}{*}{ No. } & \multirow{2}{*}{ Topics } & \multicolumn{4}{|c|}{ Levels of Objectives } & \multirow{2}{*}{$\begin{array}{c}\text { No. of } \\
\text { Questions }\end{array}$} & \multirow{2}{*}{$\%$} \\
\hline & & Knowledge & Comprehension & Application & Analysis & & \\
\hline 1 & $\begin{array}{l}\text { Endocrine } \\
\text { gland System }\end{array}$ & 2 & 3 & 4 & 3 & 12 & 40 \\
\hline 2 & $\begin{array}{l}\text { Reproduction } \\
\text { and endocrine } \\
\text { gland system }\end{array}$ & 2 & 2 & 2 & 2 & 8 & 26.67 \\
\hline 3 & $\begin{array}{l}\text { Male and female } \\
\text { genital system }\end{array}$ & 1 & 1 & 2 & 1 & 5 & 16.67 \\
\hline 4 & $\begin{array}{l}\text { Phases of man's } \\
\text { life }\end{array}$ & 1 & 1 & 1 & - & 3 & 10 \\
\hline 5 & $\begin{array}{l}\text { Menstruation and } \\
\text { hormone } \\
\text { development }\end{array}$ & 1 & 1 & - & - & 2 & 6.67 \\
\hline Total & & 7 & 8 & 9 & 6 & 30 & 100 \\
\hline
\end{tabular}

The test items were multiple-choice questions: four choices were given for each item with only one correct answer and it was first formatted in 30 items.

a. Validity

The test was submitted to a group of reviewers to give their opinions on the accuracy of the test items and their appropriateness to its objectives. Accordingly, necessary modifications (addition and omission) were made. The validity of the test was estimated to identify the correlation between levels of objectives and the test total mark. The correlation coefficient of test questions with the level of relevant total objectives were also estimated by applying Pearson equation by applying the test to a pilot sample, as shown in table (4).

Table 4. Correlation Coefficient between the Levels and the Total Mark of the Achievement Test

\begin{tabular}{lc}
\hline Domain & Pearson Coefficient \\
\hline Memorization & 0.84 \\
Comprehension & 0.81 \\
Application & 0.75 \\
Analysis & 0.73 \\
\hline
\end{tabular}

The table shows that the values of validity coefficients are significant at the level of $(0.01)$, suggesting that the test has a high degree of consistent items reflecting its validity.

\section{b. Reliability}

The reliability coefficient achieved (0.83); an acceptable value confirming the test reliability. Thus, in the final form, the test items were (30).

c. Test marking

Depended on giving one mark for each question after choosing the correct answer and zero for the incorrect one, the test final mark is equal to its items (i.e. 30).

\section{Misconceptions test}

The misconception test was set to measure the prevalence of misconceptions in the unit of (Family Planning and Reproduction). Each question of the test consisted of two parts. The first is related to a specific concept and its answer was a choice from four answers; only one choice was correct. The second part included the statement (scientific justification for my answer); the student chooses a correct answer out of four choices. The four answers of both parts were based on the students' results in the pilot study.

The initial form of the test comprised (21) items; (9) items for misconceptions about the endocrine glands system and reproduction and (12) items for misconceptions about the phases of human life. 
The test is marked by giving one mark for each correct answer in the first part and one mark for each correct answer in the second part, taking into consideration that the second part mark is not calculated if correct in case of student's mistake in the first part.

\section{a. Validity}

The test was submitted to a group of reviewers specialized in Science to verify the accuracy of scientific information, appropriateness of every question for identifying misconceptions, and appropriateness of linguistic and ideological formatting to the female students' level. The necessary modifications were made in the light of reviewers' feedback and remarks.

The correlation coefficient between students' scores in each item and their scores in the test calculated and got 0.480.79 significant at the level of (0.01), suggesting that the test has a high degree of consistent items reflecting its validity.

b. Reliability

Alpha Cronbach coefficient was calculated and got (0.97), reflecting the high reliability of the test.

c. Setting the appropriate time for the test

The time at which the first student finished answering the test and the time at which the last student did were registered. Hence, the appropriate time for answering the test was estimated as (35) minutes.

\section{Teacher's guide}

Based on the cognitive conflict strategy, a guide for the teacher was prepared. The guide's introduction, objective, significance, the given unit's objective and significance, the plan proposed for teaching the unit were set. The guide also provides an overview about the cognitive conflict strategy and its role in modifying sex education misconceptions included in the unit.

The lesson's learning outcomes were selected and the lessons were formed in a way that ensures that each lesson achieve the learning outcomes and taught using the cognitive conflict strategy. Each lesson should also include questions which measure misconceptions, evaluation and homework

The tailored lessons based on cognitive conflict strategy were submitted to a group of reviewers specialized in Science to give their opinions and check to what extent the content achieves its educational set objectives, accuracy of scientific information, appropriateness to students' level, and logical sequence of information presented. In addition to checking the study plan consistency with the cognitive conflict strategy and the appropriateness of the used evaluation methods. The lessons were modified according to the reviewers' feedback and the final form of the guide was developed.

Program's pilot study

On 9/2/2017, a pilot study was conducted to 14 intermediate second-grade students to make sure of the appropriateness of the cognitive conflict strategy to students' levels. This pilot study resulted in some observations made by both the teacher and students. They were taken into consideration when reviewing the teacher guide and formulated its final form.

\section{Results and Discussion}

\subsection{Cognitive Conflict Strategy Effectiveness}

To answer the first question and to test the first hypothesis validity, SPSS was applied to calculate T-test for the independent group and the significant differences between the two average scores of the experimental and control groups in the post- achievement test. Effect size of the independent variable (the cognitive strategy theory) to the dependent variable (achievement) was calculated using $\boldsymbol{\eta} \mathbf{2}$ (Table 5). 
Table 5. Difference Significance between the Experimental and the Control Groups Scores in the Post- Achievement Test

\begin{tabular}{|c|c|c|c|c|c|c|c|c|}
\hline Groups & Number & Mean & $\begin{array}{l}\text { Standard } \\
\text { deviation }\end{array}$ & $\begin{array}{l}\text { Degree } \\
\text { of } \\
\text { freedom }\end{array}$ & T-value & $\begin{array}{l}\text { T } \\
\text { Significance }\end{array}$ & $\begin{array}{l}\text { Effect size } \\
\eta 2\end{array}$ & $\begin{array}{l}\text { Effect size } \\
\text { significance }\end{array}$ \\
\hline Experimental & 28 & 25.81 & 0.95 & \multirow{2}{*}{54} & \multirow{2}{*}{4.09} & \multirow{2}{*}{$\begin{array}{l}\text { Significant at } \\
0.01\end{array}$} & \multirow{2}{*}{0.77} & \multirow[t]{2}{*}{ Big } \\
\hline Control & 28 & 20.91 & 2.61 & & & & & \\
\hline
\end{tabular}

The table shows that there are statistically significant differences at the level of $(0.01)$ on the achievement test among the experimental and control groups students, favoring the experimental group. Hence, the first hypothesis is verified, as the achievement level of the experimental group students who were taught by the cognitive conflict strategy is higher than the achievement level of the control group students who were taught by the traditional method.

The effect size of the independent variable (cognitive conflict strategy) on the dependent one (cognitive achievement) is big, asserting the effectiveness of the cognitive conflict strategy in developing achievement among intermediate second-grade students. Thus, the first question is answered.

These results are consistent with (Jawad, 2015) (Al-Otaibi, 2015) (Alabous \& Alani, 2013) (Almamouri, 2011) (Albayati \& Mehdi, 2009) (Demirciog et al., 2005) (Zohar \& Kravetsky, 2003), concluding the effectiveness of the cognitive conflict strategy in improving student academic achievement. This finding can be explained that the use of cognitive conflict strategy helped the experimental group students effectively absorb the subject more than the control group students who were taught using the traditional method. In the traditional method, the teacher is the center of the educational process that depends on student memorization of the textbook without actually understanding its content or actively interacting with it. On the contrary, the cognitive conflict strategy helped students develop the questioning and critical thinking skills, which represents the basis of scientific discoveries and innovations. In addition, it helped the experimental group students practice prediction during the class as they reach to the hypotheses and predictions after being explained by the teacher. As the strategy provides an educational situation that increases student academic achievement and motivation for studying the subject. Furthermore, the cognitive conflict strategy help students have correct judgement and proper perception. Through the strategy, students have correct concepts and adjusted way of thinking about error, as it leads to the identification of a disciplined and systematic scientific understanding of the reality of the thing. It also develops the student's ability to think and use conceptual structure in new situations, which helps understand the correct concepts and thus increase the academic achievement. Finally, the strategy helps students develop scientific curiosity and motivate them to seek interpretation of scientific phenomena.

\subsection{Modifying Sex Education Misconception}

To answer the second question and to test the second hypothesis validity, SPSS was applied to calculate T-test for the independent group and the significant differences between the two average scores of the experimental and control groups in the post- achievement test. Effect size of the independent variable (the cognitive strategy theory) to the dependent variable (misconception) was calculated using $\boldsymbol{\eta} \mathbf{2}$ (Table 6).

Table 6. Difference Significance between the Scores of the Experimental and the Control Groups in the Post-Misconception Test

\begin{tabular}{llccccccc}
\hline Groups & Number & $\begin{array}{l}\text { Arithmetic } \\
\text { mean }\end{array}$ & $\begin{array}{l}\text { Standard } \\
\text { deviation }\end{array}$ & $\begin{array}{l}\text { Degree of } \\
\text { freedom }\end{array}$ & T-value & T Significant & $\begin{array}{l}\text { Effect size } \\
\boldsymbol{\eta} 2\end{array}$ & $\begin{array}{l}\text { Effect size } \\
\text { significance }\end{array}$ \\
\hline Experimental & 28 & 23.71 & 0.90 & 54 & 4.09 & Significant at & 0.76 & Big \\
Control & 28 & 21.61 & 2.57 & & & 0.01 & & \\
\hline
\end{tabular}

The table shows that there are statistically significant differences at the level of $(0.01)$ on the misconceptions among the students of the experimental and control groups in favor of the experimental group. Thus, the second hypothesis is verified, indicating that misconceptions are modified among the experimental group students who were taught by the cognitive conflict strategy more than the control group students who were taught by the traditional method.

The effect size of the independent variable (cognitive conflict) on the dependent one (misconceptions) is big, emphasizing the effectiveness of the cognitive conflict strategy in modifying the misconceptions of intermediate second-grade students. 
Results are consistent with Al-Mahdi (2017), Albeleesi (2006), Tolba (2006), and Tsai (2003), that the cognitive conflict strategy has a positive effect on the modification of student misperceptions. It can be explained that the use of cognitive conflict strategy helped present the content of the chapter entitled "family planning and reproduction" in detail. Teacher's interest in identifying female students' misconceptions before teaching and taking them into consideration helped modify their misconceptions into correct scientific concepts. Furthermore, the cognitive conflict strategy works on the conceptual formation among students through creating knowledge conflict between the previously acquired concepts of sex education dimensions and the correct concepts. This process motivates their curiosity to resolve this conflict and bring about adaptation and harmonization and access to the scientific concepts and principles of the topic under discussion. Thus, it can be concluded that the cognitive conflict strategy is effective in modifying student misconceptions.

\section{Recommendations}

1. Directing science teachers to discover, diagnose and treat the prevailing misconceptions among students using modern teaching strategies and techniques, such as oral and written tests and pre-diagnose tests.

2. Holding training courses and workshops for science teachers on cognitive conflict strategy.

3. Including some issues and problems of sex education in various educational stages.

4. Setting a teacher's and a student's guide about how to overcome the prevailing misconceptions through the proper activities and guidance.

\section{References}

Abdel Alazeem, A. (2008). Sex education in Islam (1st ed.). Alexandria: Alesraa Library.

Abdel-Wareth, S., \& Said, M. (2012). The effectiveness of cognitive conflict strategy in modifying misconceptions in physics and developing critical thinking among first grade secondary students. Journal of Educational and Psychological Sciences, Bahrain, 13(2), 305-337.

Abdullah, A., \& Yawar, A. (2012). The reality of sex education in secondary schools for girls from students' perspective. Journal of the Faculty of Basic Education, University of Babylon, 290-307.

Abu Halima, J. A. (2008). The effectiveness of a multimedia program employing contradicting events in developing nutrition literacy among fifth-grade students in science (MA Thesis). Gaza, Palestine.

Aga, I., \& Lulu, F. (2009). Teaching science in general education (2nd ed.). Afaaq Library, Faculty of Education, Islamic University.

Ahmed, M. R. (2008). The effectiveness of Sushman strategy for the investigation of contradicting events in achievement and the development of some thinking skills among first-grade students. Journal of Faculty of Education, 66(1), 125-175. Mansoura University.

Alaabidly, O. (2001). Online sexual abuse of children. A paper presented at The Conference of Child Protection against Maltreatment and Neglect by Family Protection and Legislation Promotion, Bahrain Society for Child Development and UNICEF, Manama, Bahrain.

Alaamarin, Y. (2011). The perspectives of biology teachers on sex education of the curricula of biology to cycle II of basic education. Journal of Damascus University, 27(3), 375-411.

Alabous, T., \& Alani, R. (2013). The impact of cognitive conflict strategy on the development of scientific concepts and trends among basic elementary stage students in Jordan. Najah University Journal of Research, 27(1), 201-223.

Albayati, M., \& Mehdi, E. (2009). The impact of using conflicting events strategy in the imagination of second-grade students and their scientific thinking. Al-Fath Journal, 12(43), 233-272.

Albeleesi, E. (2006). The effectiveness of contradictions strategy in modifying alternative perceptions among tenth grade students. MA thesis. Gaza, Islamic University.

ALford, S. (2008). Science and success, programs that work to prevent teen pregnancy, HIV\& sexually transmitted infections. Washington DC: Advocates for youth.

Alhalafawi, K. (2009). Teaching Effectiveness Using Cognitive conflict maps in Correcting and Developing Science Misconceptions among Intermediate Students in KSA. Journal of Scientific Education, 12, 63-78. 
Alison, P. (2007). Sex Education in Washington Public Schools, are students learning what they need to know? Healthy Youth Alliance.

Al-Jokhdar, A. (2000). Population education. A paper presented to the International Forum on Population, Reproductive Health and Gender Issues, October 20, Egypt, Islamic Perspective, Cairo.

Al-Kashah, A. (2004). Attitudes toward teaching sex education in relation to sex and specialization variables among teachers of government schools in Palestine. Journal of Educational and Psychological Sciences, 5(3), 210-238.

Al-Mahdi, E. (2017). The impact of using the strategy of contrasting events in modifying alternative perceptions and developing problem solving skills in chemistry among the tenth grade students in the schools of Tulkarem Education Directorate. Master Thesis, An-Najah National University, Nablus.

Almamouri, E. (2011). The impact of using discrepant events method on the achievement and creative thinking skills of fourth grade students in scientific physics. Al-Fath Journal, 46, Diyala, Iraq.

Alnashiry, M. (2008). Alternative perceptions about some genetic concepts among the $3^{\text {rd }}$ grade intermediate students in Kunfuda Governorate (Unpublished MA. thesis). College of Education, Umm Al-Qura University, Mecca.

Al-Otaibi, N. (2015). Effectiveness of cognitive conflict strategy in the development of achievement and some mental habits in science among second grade students in Mecca (MA Thesis). Umm Al-Qura University, KSA.

Alqadi, S. (2006). Sex education in Islam and its provision to school and university students (1st ed.). Cairo: Dar Elfikr Elarabi.

Al-Rubaiyi, A., Al-Musawi, F., \& Mustafa, S. (2015). The effect of the intellectual opposition schemes in the acquisition and retention of biological concepts for the fifth preparatory scientific class. Journal of College of Basic Education for Educational and Human Sciences, 19, 314-327.

Al-Zind, W., \& Obaidat, H. (2010). Educational curriculum. Irbid: World of the Book.

Arab Office of Education in Gulf States. (2017). Sexual education and health: Reality-vision-challenges. A paper presented at the National Forum for Sexual Education, University of Tlemcen, Algeria.

Bahjat, R. (2001). Teaching Natural Science: A Modern Vision. Cairo: Alam Alkotob.

Baz, T., \& Bwanah, A. (2008). The impact of using cognitive conflict maps as an educational tool in changing misconceptions in science among eighth-grade students in Jordan. Educational Journal, 87.

Becy, A. (2010). Sex Education Report. The sex Education forum, Hansard society London, 112.

Berger, D., Bernard, S., Carvalho, G., Munoz, F., \& Clément, P. (2007). Sex education: Analysis of teachers' and future teachers' conceptions from 12 countries of Europe, Africa and Middle East.

Demirciog, C. G., \& Others. (2005). Conceptual change achieved through a new program on acids bases. Research in Science Teaching, 32(9), 971-991.

Fanlder, G. S., Riley S. C., \& Glasiers, A. (2004). Teaching Sex Education Improves Medical Students Confidence in Dealing with Sexual Health Issues. Contraception, 2(70), 135-139. https://doi.org/10.1016/j.contraception.2004.03.010

Farton, A. (2004). Emotional educational approach for adolescents. Beirut: Dar Qabes.

González-Espada, W., Birriel, J., \& Birriel, I. (2010). Discrepant events: A challenge to students' intuition. The Physics Teacher, 48(8), 508-511. https://doi.org/10.1119/1.3502499

Jawad, M. (2015). Effectiveness of the cognitive conflict strategy in achievement and development of critical thinking among fourth-grade students in physics. Journal of the Faculty of Basic Education for Educational and Human Sciences, 22, 438-472.

Jumah, A. (2008). Sex education concepts and teaching methods in Islamic education textbooks of in two educational phases (MA Thesis). Faculty of Education, University of Damascus.

Mady, E. (2011). The impact of cognitive conflict schemes on developing concepts and resolving the genetic issue among the tenth grade students (MA. thesis). College of Education, Islamic University in Gaza.

Maximos, W. (2003). Constructivism in teaching and learning mathematics. A paper presented at the $3^{\text {rd }}$ Arab Conference on the Systemic Approach in Teaching and Learning, SCE, Ain Shams University, Cairo.

Mosher, W. (2005). Sexual behavior and selected health measures: men and women 15-44 years of age, United States, 
2002. Advance Data, 15(362), 1-55.

Najdi, A., Abdel Hadi, M., \& Rashed, A. (2003). New methods and strategies for teaching Science. Reference Series in Education and Neuroscience, Book 27, Cairo: Arab Thought House.

Ogunjimi, L. O. (2006). Attitude of Students and Parents towards the Teaching of Sex Education, in Secondary Schools in Cross Rivers State. Educational Research and Review, 9(1), 347-349.

Orji, E. O., \& Esimani, O. A. (2003). Introduction of sex Education into Nigerian Schools: the Parents', Teachers' and Students' Perspectives. Obstet Gynaecol, 23(2), 185-188. https://doi.org/10.1080/0744361031000074772

Pyram, A. A. (2002). The impact of using cognitive conflict strategy on the development of thinking skills in the science among ninth-grade students in Gaza (MA Thesis). Palestine.

Ramiro, M. (2008). Perceptions of Portuguese teachers about sex education. Rev sautde publica, 4(42), 1-8.

Reis, M., Ramiro, L., Gaspardematos, M., \& Diniz, J. (2011). The effects of sex education in promoting sexual and reproductive health in Portuguese University student. Social and Behavioral Sciences, 29, 477-485. https://doi.org/10.1016/j.sbspro.2011.11.266

Salah, S. (2000). Public school teachers' attitudes towards the teaching of sex education in Northern Governorates of Palestine (Unpublished MA. thesis). An-Najah National University, Nablus, Palestine

Salem, S. (2006). The impact of cognitive conflict strategy in science teaching on the development of achievement, science processes and creative thinking skills among sixth graders in basic education. Journal of Scientific Education, 9(50), 1-50.

Shulman, D. (2001). Using psychological theories to teach children sexual abuse prevention skills: The safety through education and practice program. DAI, 61(10).

Tolba, I. (2006). The effectiveness of using the cognitive conflict maps in correcting some alternative conceptions on the physical issues among the $1^{\text {st }}$ secondary grade students. Journal of Scientific Education, 9(1), 55-110.

Tsai, C. (2000). Enhancing science instruction: The use of conflict map. International Journal of Science Education, 22(3), 285-302. https://doi.org/10.1080/095006900289886

Zahran, H. (2005). Childhood and Adolescence Psychology. Alm El-Kutb, Cairo.

Zeitoun, K. (2002). Teaching science for understanding: A constructive perspective (1st ed.). Cairo: Alam Alkotob.

Zohar, A., \& Kravestsky, S. A. (2003). Cognitive conflict direct teaching and student's academic level. Paper presented at the annual meeting of the national association for research in science teaching, Philadelphia (23-26) march. 